\title{
Assessment of maxillary sinus in gender determination- A CBCT study
}

\author{
Praveen Kumar $^{1, *}$, Balaji Pachipulusu ${ }^{2}$, Poornima Govindraju ${ }^{3}$ \\ ${ }^{1}$ Post Graduate Student, ${ }^{2}$ Professor \& HOD, ${ }^{3}$ Professor, Dept. of Oral Medicine \& Radiology, Rajarajeswari Dental college and \\ Hospital, Bangalore, Karnataka, India
}

*Corresponding Author:

Email: praveen2007223@gmail.com

\begin{abstract}
Introduction: Determination of gender is an important aspect of forensic odontology. CBCT measurement of maxillary sinuses can be useful in determination of gender. Aim: To assess the sexual dimorphism using dimensions of maxillary sinus in CBCT images.

Objectives: 1) To determine whether there are morphological and morphometric variations among genders. 2) To assess which the most reliable predictor of sex among width, length \& height.

Materials and Method: The present study was conducted in Department of Oral Medicine and Radiology. Retrospectively 40 CBCT scans of bilateral maxillary sinus were retrieved from the database after excluding the subjects with pathologies of maxillary sinus like cyst, tumours and fractures and images with errors or artefacts obscuring maxillary sinus. Two independent observer measured three distances of the maxillary sinus (width, length, height) in axial and coronal view.

Results: Parameters of Maxillary Sinus for male were greater than females. Width and height was better predictor than length with $60 \%$ accuracy than $50 \%$ accuracy for length.

Conclusion: We suggest that CBCT measurement of Maxillary Sinus can be used as supplementary tool for gender determination in forensic science.
\end{abstract}

Keywords: Cone Beam Computed Tomography, Gender, Maxillary Sinus.

\section{Introduction}

Natural calamities and crime continue to perish in human life despite of breakthrough in science and technology. ${ }^{1}$ Forensic investigator receives unknown skeletal remains for identification of age and gender. ${ }^{2}$ For determination of gender skull, pelvis and long bones with an epiphysis and metaphysis in skeletal can be used. ${ }^{3}$ Skeletal remains are used for sex determination as bones of the body are the last to perish after death. ${ }^{4}$ Maxillary sinuses (MS) can be used for identification since they remain intact, although other bones may be disfigured. ${ }^{5}$

Various techniques have been used to assess sexual dimorphism varying from dry skull or cadaveric studies to use of radiographic techniques or combination of both. Imaging modalities involving panoramic radiography, CT imaging and $\mathrm{CBCT}$ have been used. CBCT is a preferred $3 \mathrm{D}$ imaging modality in maxillofacial region since it is a volumetric imaging modality which is ideal for capturing anatomic structures with less radiation exposure, cost effective, shorter acquisition time than CT. Hence, this study was undertaken with an aim to assess the sexual dimorphism using dimensions of maxillary sinus in CBCT images.

\section{Materials and Method}

The Present study was conducted in Department of Oral Medicine \& Radiology after getting approval from the institutional ethical committee. Retrospectively 40 CBCT scans of bilateral maxillary sinus were retrieved from the database after excluding the subjects with pathologies of maxillary sinus like cyst, tumours and fractures and images with errors or artefacts obscuring maxillary sinus.

\section{Radiographic Investigation}

Two independent observer measured three distances (width, length, height) in axial and coronal view. The morphometric of the maxillary sinus were performed in the following methods (Refer Fig.).

a. Width (axial view): Longest distance perpendicular from medial wall of the sinus to the most lateral wall of lateral process of the maxillary sinus.

b. Length (axial view): Longest distance from the most anterior point to the most posterior point of the medial wall.

c. Height (coronal view): Longest distance from the lowest point of the sinus floor to the highest point of the sinus roof. 


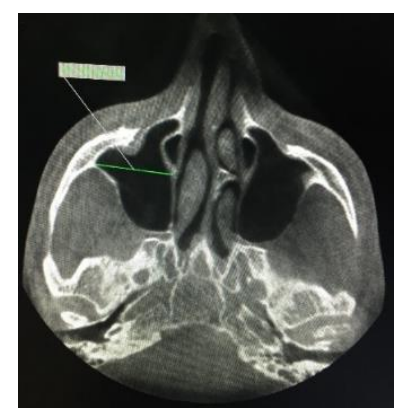

Width

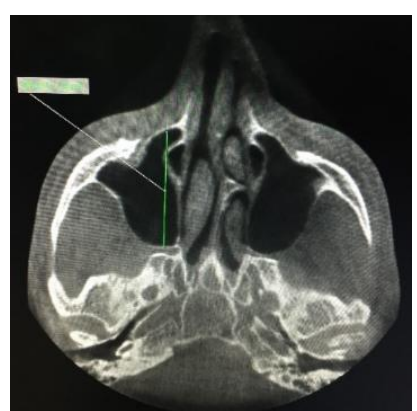

Length

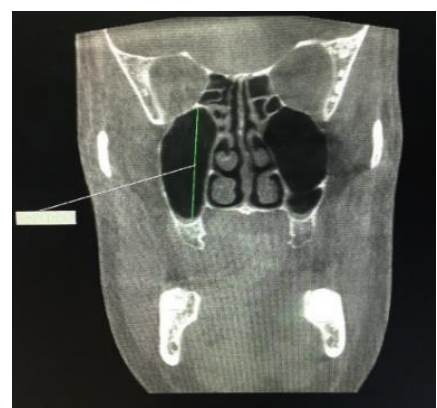

Height

\section{Reliablity}

For inter and intra observer reliability $25 \%$ (10 $\mathrm{CBCT}$ images) of the sample were randomly selected and analysed again by 2 observers using Intraclass Correlation Coefficient.

Statistical analysis was performed by using SPSS (Version 22). For comparing the morphological and morphometric parameters between genders independent ' $\mathrm{t}$ ' test was performed. To assess the relationship between different morphometric parameters on right and left maxillary sinus Pearson correlation test was used.

To assess whether the measurement of the maxillary sinuses could be used for sex determination a discriminant functional analysis was performed. To generate an equation that could reliably classify the observations according to sex, multiple logistic regression was performed. To determine the fit of the regression model as well as to identify the optimum cut off criteria. The Receiver Operating Curve (ROC) analysis was used. The level of significance [P- value] was set at $\mathrm{P}<0.05$.

\section{Results}

In this study overall agreements for intra and inter observer performances had well to excellent reliability with Intra class Coefficient vary ranging from 0.83 to 0.96. In the present study, when compared to males as shown in graph $1 \&$ graph 2 the overall parameter of the maxillary sinus of the female were significantly smaller. To assess the relationship between morphometric parameter in right and left maxillary sinus Pearson correlation test was done which showed statistically significant values as shown in table $1 \&$ table 2 .

$65 \%$ of original group could be correctly classified as males and $55 \%$ as female with the right width. $50 \%$ of the original group could be correctly classified as males and $45 \%$ as female with the left width (Table 3). 50\% of original group could be correctly classified as male and $50 \%$ as females with right length. 50\% of original group could be correctly classified as male and $60 \%$ as females with left length (Table 4). $50 \%$ of original group could be correctly classified as males and as female with the right height. $50 \%$ of original group could be correctly classified as males and $35 \%$ as female with the left height (Table 5).

Using the multiple logistic regression the following formula or equation can be used for gender determination from the measurement of right maxillary sinus.

Sex $=4.25-(0.07 \times$ width $)-(0.02 \times$ length $)-(0.06$ xheight)

Following formula can be used for gender determination from the measurement of left maxillary sinus.

Sex $=2.225+(0.04 \times$ width $)-(0.09 \times$ length $)+(0.01$ xheight)

Proposed optimum cut off of -1.02 for the right maxillary and -1.10 for left maxillary sinus respectively was obtained by ROC analysis. Males were classified when values were greater than cut off and those with lower were classified as females.

Graph 1: Gender wise comparison of morphological $\&$ morphometric parameters of right maxillary sinus

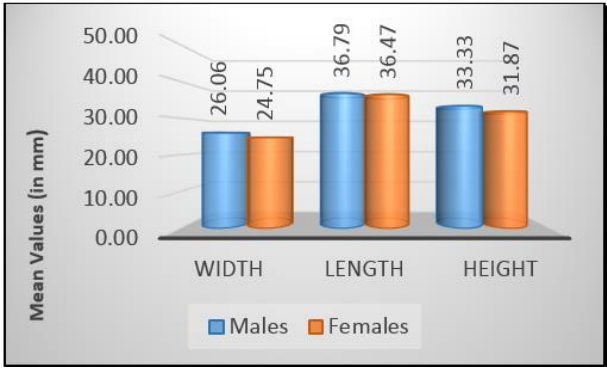

Graph 2: Genderwise comparison of morphological $\&$ morphometric parameters of left maxillary sinus

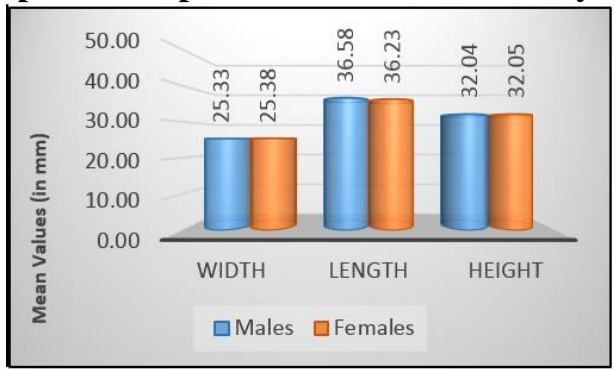


Table 1: Pearson correlation test to assess the relationship between morphometric parameters in right maxillary sinus

\begin{tabular}{|c|c|l|c|c|c|}
\hline Gender & Parameters & Values & Width & Length & Height \\
\hline \multirow{4}{*}{ Males } & \multirow{4}{*}{ Width } & $\mathrm{r}$ & 1 & 0.25 & 0.50 \\
\cline { 3 - 6 } & & $\mathrm{p}$-Value & & 0.29 & $0.03^{*}$ \\
\cline { 3 - 6 } & \multirow{2}{*}{ Length } & $\mathrm{r}$ & 0.25 & 1 & 0.11 \\
\cline { 3 - 6 } & & $\mathrm{p}$-Value & 0.29 & & 0.65 \\
\cline { 3 - 6 } & \multirow{2}{*}{ Height } & $\mathrm{r}$ & 0.50 & 0.11 & 1 \\
\cline { 3 - 6 } & & $\mathrm{P}$-Value & $0.03^{*}$ & 0.65 & \\
\hline \multirow{4}{*}{ Wemales } & $\mathrm{r}$ & 1 & 0.32 & 0.50 \\
\cline { 3 - 6 } & & $\mathrm{p}$-Value & & 0.17 & $0.02^{*}$ \\
\cline { 3 - 6 } & \multirow{2}{*}{ Length } & $\mathrm{r}$ & 0.32 & 1 & 0.11 \\
\cline { 3 - 6 } & & $\mathrm{p}$-Value & 0.17 & & 0.66 \\
\cline { 3 - 6 } & \multirow{2}{*}{ Height } & $\mathrm{r}$ & 0.50 & 0.11 & 1 \\
\cline { 3 - 6 } & & $\mathrm{p}$-Value & $0.02^{*}$ & 0.66 & \\
\hline
\end{tabular}

Table 2: Pearson correlation test to assess the relationship between morphometric parameters in left maxillary sinus

\begin{tabular}{|c|c|l|c|c|c|}
\hline Gender & Parameters & Values & Width & Length & Height \\
\hline Males & \multirow{4}{*}{ Width } & $\mathrm{r}$ & 1 & 0.54 & 0.44 \\
\cline { 3 - 6 } & & $\mathrm{p}$-value & & $0.01^{*}$ & 0.05 \\
\cline { 3 - 6 } & \multirow{4}{*}{ Length } & $\mathrm{R}$ & 0.54 & 1 & 0.39 \\
\cline { 3 - 6 } & \multirow{3}{*}{ Height } & $\mathrm{p}$-value & $0.01^{*}$ & & 0.09 \\
\cline { 3 - 6 } & & $\mathrm{p}$-Value & 0.05 & 0.39 & 1 \\
\hline \multirow{3}{*}{ Females } & \multirow{2}{*}{ Width } & $\mathrm{r}$ & 1 & 0.09 & \\
\cline { 3 - 6 } & & $\mathrm{p}$-Value & & $0.005^{*}$ & $0.001^{*}$ \\
\cline { 3 - 6 } & \multirow{2}{*}{ Length } & $\mathrm{r}$ & 0.61 & 1 & 0.33 \\
\cline { 3 - 6 } & & $\mathrm{p}$-Value & $0.005^{*}$ & & 0.15 \\
\cline { 3 - 6 } & \multirow{2}{*}{ Height } & $\mathrm{r}$ & 0.69 & 0.33 & 1 \\
\cline { 3 - 6 } & & $\mathrm{p}$-Value & $0.001^{*}$ & 0.15 & \\
\hline
\end{tabular}

Table 3: Classification results of discriminant functional analysis of Rt_width ${ }^{\mathrm{b}, \mathrm{c}}$ and $\mathrm{Lt}_{\text {_width }}{ }^{\mathrm{d}, \mathrm{e}}$ of maxillary sinus

\begin{tabular}{|c|c|c|c|c|c|c|c|}
\hline & \multirow[t]{2}{*}{ Gender } & \multirow[t]{2}{*}{ n \& \% } & \multirow[t]{2}{*}{ Values } & \multicolumn{2}{|c|}{ PGM - Rt Width } & \multicolumn{2}{|c|}{ PGM - Lt Width } \\
\hline & & & & Males & Females & Males & Females \\
\hline \multirow{4}{*}{ Original } & Males & \multirow[t]{2}{*}{$\mathrm{n}$} & 20 & 13 & 7 & 10 & 10 \\
\hline & Females & & 20 & 9 & 11 & 11 & 9 \\
\hline & Males & \multirow[t]{2}{*}{$\%$} & 100 & 65 & 35 & 50 & 50 \\
\hline & Females & & 100 & 45 & 55 & 55 & 45 \\
\hline \multirow{4}{*}{$\begin{array}{c}\text { Cross- } \\
\text { validated }\end{array}$} & Males & \multirow[t]{2}{*}{$\mathrm{n}$} & 20 & 13 & 7 & 2 & 18 \\
\hline & Females & & 20 & 9 & 11 & 17 & 3 \\
\hline & Males & \multirow[t]{2}{*}{$\%$} & 100 & 65 & 35 & 10 & 90 \\
\hline & Females & & 100 & 45 & 55 & 85 & 15 \\
\hline
\end{tabular}

Note: PGM - Predicted Group Membership

a. Cross validation is done only for those cases in the analysis. In cross validation, each case is classified by the functions derived from all cases other than that case

b. $\quad 60.0 \%$ of original grouped cases correctly classified

c. $60.0 \%$ of cross-validated grouped cases correctly classified

d. $47.5 \%$ of original grouped cases correctly classified

e. $12.5 \%$ of cross-validated grouped cases correctly classified 
Table 4: Classification results of discriminant functional analysis of Rt_length ${ }^{\mathrm{b}, \mathrm{c}}$ and Lt_length ${ }^{\mathrm{d}, \mathrm{e}}$ of maxillary sinus

\begin{tabular}{|c|c|c|c|c|c|c|c|}
\hline & \multirow[t]{2}{*}{ Gender } & \multirow[t]{2}{*}{ n \& \% } & \multirow[t]{2}{*}{ Values } & \multicolumn{2}{|c|}{ PGM - Rt Length } & \multicolumn{2}{|c|}{ PGM - Lt Length } \\
\hline & & & & Males & Females & Males & Females \\
\hline \multirow[t]{4}{*}{ Original } & Males & \multirow[t]{2}{*}{$\mathrm{n}$} & 20 & 10 & 10 & 10 & 10 \\
\hline & Females & & 20 & 10 & 10 & 8 & 12 \\
\hline & Males & \multirow[t]{2}{*}{$\%$} & 100 & 50 & 50 & 50 & 50 \\
\hline & Females & & 100 & 50 & 50 & 40 & 60 \\
\hline \multirow{4}{*}{$\begin{array}{c}\text { Cross- } \\
\text { validated }\end{array}$} & Males & \multirow[t]{2}{*}{$\mathrm{n}$} & 20 & 10 & 10 & 9 & 11 \\
\hline & Females & & 20 & 10 & 10 & 8 & 12 \\
\hline & Males & \multirow[t]{2}{*}{$\%$} & 100 & 50 & 50 & 45 & 55 \\
\hline & Females & & 100 & 50 & 50 & 40 & 60 \\
\hline
\end{tabular}

Note: PGM - Predicted Group Membership

a. Cross validation is done only for those cases in the analysis. In cross validation, each case is classified by the functions derived from all cases other than that case.

b. $\quad 50.0 \%$ of original grouped cases correctly classified.

c. $50.0 \%$ of cross-validated grouped cases correctly classified.

d. $55.0 \%$ of original grouped cases correctly classified.

e. $52.5 \%$ of cross-validated grouped cases correctly classified.

Table 5: Classification results of discriminant functional analysis of Rt_height ${ }^{\mathrm{b}, \mathrm{c}}$ and Lt_height ${ }^{\mathrm{d}, \mathrm{e}}$ of maxillary sinus

\begin{tabular}{|c|c|c|c|c|c|c|c|}
\hline & \multirow[t]{2}{*}{ Gender } & \multirow[t]{2}{*}{ n \& \% } & \multirow[t]{2}{*}{ Values } & \multicolumn{2}{|c|}{ PGM - Rt Height } & \multicolumn{2}{|c|}{ PGM - Lt Height } \\
\hline & & & & Males & Females & Males & Females \\
\hline \multirow[t]{4}{*}{ Original } & Males & \multirow[t]{2}{*}{$\mathrm{n}$} & 20 & 10 & 10 & 10 & 10 \\
\hline & Females & & 20 & 6 & 14 & 13 & 7 \\
\hline & Males & \multirow[t]{2}{*}{$\%$} & 100 & 50 & 50 & 50 & 50 \\
\hline & Females & & 100 & 30 & 70 & 65 & 35 \\
\hline \multirow{4}{*}{$\begin{array}{c}\text { Cross- } \\
\text { validated }\end{array}$} & Males & \multirow[t]{2}{*}{$\mathrm{n}$} & 20 & 10 & 10 & 0 & 20 \\
\hline & Females & & 20 & 6 & 14 & 20 & 0 \\
\hline & Males & \multirow[t]{2}{*}{$\%$} & 100 & 50 & 50 & 0 & 100 \\
\hline & Females & & 100 & 30 & 70 & 100 & 0 \\
\hline
\end{tabular}

Note: PGM - Predicted Group Membership

a. Cross validation is done only for those cases in the analysis. In cross validation, each case is classified by the functions derived from all cases other than that case

b. b. $60.0 \%$ of original grouped cases correctly classified

c. c. $60.0 \%$ of cross-validated grouped cases correctly classified

d. d. $42.5 \%$ of original grouped cases correctly classified

e. e. $0.0 \%$ of cross-validated grouped cases correctly classified

Table 6: Intra rater reliability between the 02 observations recorded at different time intervals for morphometric measurements

\begin{tabular}{|c|c|c|c|c|c|}
\hline Sides & Parameters & \multirow{2}{*}{ ICC } & \multicolumn{2}{|c|}{ 95\% Conf. Interval } & \multirow{2}{*}{ P-Value } \\
\cline { 3 - 5 } & & & Lower & Upper & \\
\hline Right & Width & 0.89 & 0.70 & 0.97 & $<0.001^{*}$ \\
\cline { 2 - 5 } & Length & 0.94 & 0.84 & 0.98 & $<0.001^{*}$ \\
\cline { 2 - 5 } & Height & 0.80 & 0.47 & 0.94 & $0.001^{*}$ \\
\hline \multirow{2}{*}{ Left } & Width & 0.94 & 0.84 & 0.98 & $<0.001^{*}$ \\
\cline { 2 - 5 } & Length & 0.88 & 0.68 & 0.97 & $<0.001^{*}$ \\
\cline { 2 - 5 } & Height & 0.83 & 0.56 & 0.95 & $<0.001^{*}$ \\
\hline
\end{tabular}


Table 7: Inter rater reliability between 02 observers recorded at a given time interval for morphometric measurements

\begin{tabular}{|c|c|c|c|c|c|}
\hline Sides & Parameters & \multirow{2}{*}{ ICC } & \multicolumn{2}{|c|}{ 95\% Conf. Interval } & \multirow{2}{*}{ P-Value } \\
\cline { 3 - 6 } & & & Lower & Upper & \\
\hline \multirow{3}{*}{ Right } & Width & 0.90 & 0.74 & 0.97 & $<0.001^{*}$ \\
\cline { 2 - 6 } & Length & 0.96 & 0.89 & 0.99 & $<0.001^{*}$ \\
\cline { 2 - 6 } & Height & 0.86 & 0.66 & 0.93 & $0.001^{*}$ \\
\hline \multirow{3}{*}{ Left } & Width & 0.88 & 0.68 & 0.97 & $<0.001^{*}$ \\
\cline { 2 - 6 } & Length & 0.94 & 0.84 & 0.98 & $<0.001^{*}$ \\
\cline { 2 - 6 } & Height & 0.85 & 0.65 & 0.93 & $<0.001^{*}$ \\
\hline
\end{tabular}

* - Statistically Significant

Note: ICC - Intraclass Correlation Coefficient

ICC values $<0.50$ - Poor reliability

0.50 - 0.75 - Moderate reliability

$0.75-0.90-$ Good reliability

$>0.90$ - Excellent reliability

\section{Discussion}

Gender identification from remains of human skeleton is an important forensic procedure, As reported if entire skeleton is available gender can be determined with accuracy of 100\%, 98\% accuracy can be achieved with pelvis and skull. ${ }^{6}$ Present study was designed to determine reliability and accuracy of maxillary sinus dimensions as a method for gender determination using CBCT. According to current study comparing mean values (width, length, height) between males and females, values of male were relatively greater than female. Similar results were obtained in previous studies done by Bangi et al, ${ }^{2}$ Teke et al, ${ }^{3}$ Tambawala et al ${ }^{5,7,8-10}$.

Pearson correlation coefficient ' $r$ ' was positive in morphometric parameters (width, length, height). Similar results were obtained in Tambawala et al study. ${ }^{7}$ In the present study right side parameters were relatively greater than left side which was in accordance with Bangi BB et al study. ${ }^{2}$ Using discriminant functional analysis, present study width was correctly classified in $60 \%$ of cases, length in $50 \%$, height in $60 \%$ of cases which revealed width and height was better predictor than length which was almost similar to study done by Teke et al. He reported an accuracy of $69.4 \%$ in females and $69.2 \%$ in males and mean accuracy of $69.3 \%$ using only length, width and height measurement of maxillary sinus. $^{3}$

Maxillary sinuses are significantly larger in males than in females and the right maxillary sinus is larger than left in both genders according to Bangi $\mathrm{B}$ et al. ${ }^{2}$ In context to length, height and width dimension, female showed statistically significant lower values for both left and right maxillary sinus. ${ }^{6,7}$ Maxillary Sinus height was the best discriminant parameter with overall accuracy of $71.6 \%$ according to Tambawala SS et al. $^{7}$ Overall accuracy of $69.8 \%$ was observed in Maxillary Sinus length and was considered best discriminant parameter according to Sharma SK et al. ${ }^{3,6}$ Maxillary Sinus of males were found narrower than female in Zululand and wider in males than females in Europe. ${ }^{3,12}$ Small sample size limits interpretation of our finding. Further investigation in large sample size would be necessary to confirm our findings.

\section{Conclusion}

The present study showed that parameters of Maxillary Sinus of male were greater than female. Height, Width \& length had positive correlation among themselves in both male and female which was statistically significant. Height and width were better predictor than length. We suggest that measurement of maxillary sinus together with other bones can be used for determination of gender when whole skeletal is not available. Hence, CBCT measurements of Maxillary Sinus can be used as supplementary tool for gender determination in forensic science.

\section{Conflict of Interest: Nil}

\section{References}

1. Saranya V, Malathi N. Forensic odontology: A brief review. Sri Ramchandra. J Med 2014;7:22-28.

2. 2.Bangi BB, Ginjupally U,Nadendla L, Vadla B. 3D Evaluation of Maxillary Sinus Using Computed Tomography: A Sexual Dimorphic Study. Int J Dent 2017; Article ID 9017078, 4.

3. 3.Teke HY, Duran S, Canturk N and Canturk G. Determination of gender by measuring the size of the maxillary sinuses in computerized tomography scans. $J$ Surg Radiol Anat 2007;29:9-13.

4. 4.Uthman AT, Al-Rawi NH, Al- Naaimi AS, Al- Timmi JF. Evaluation of maxillary sinus dimensions in gender determination using helical CT scanning. J Forensic Sci 2011;56;403-8.

5. Sidhu R, Chandra S, Devi P, Taneja N, Sah K, Kaur N. Forensic importance of maxillary sinus in gender determination: A morphometric analysis from Western Uttar Pradesh, India. Eur J Gen Dent 2014;3:53-6.

6. Urooge A, Patil BA. Sexual Dimorphism of maxillary sinus: A morphometric analysis using Cone Beam Computed Tomography. J Clin Diagn Res 2017;11(3);6770.

7. Tambawala SS, Karjodkar FR, Sansare K, Prakash N. Sexual dimorphism of maxillary sinus using cone beam computed tomography, Egypt J Forensic Sci 2015;6(2):120-5. 
8. Paknhad M, Sahidi S, Zarei Z. Sexual Dimorphism of maxillary sinus dimensions using cone beam computed tomography. J Forensic Sci 2017;62(2);395-98.

9. Sharma SK, Jehan M, Kumar A. Measurements of Maxillary Sinus Volume and Dimensions by Computed Tomography Scan for Gender Determination. J Anat Soc Ind 2014;63(1):36-42.

10. Jehan M, Bhadkaria V, Trivedi A, Sharma S. Sexual dimorphism of bizygomatic distance \& maxillary sinus using CT scan. J Med Dent Sci 2014;13(3):91-5.

11. Sharan A, Madjar D. Maxillary sinus pneumatization following extractions: a radiographic study. Int J Oral Maxillof Implants 2008;23:48-56.

12. Lee Fernandes C. Forensic ethnic identification of crania. The role of the maxillary sinus- a new approach. Am J Forensic Med Pathol 2004;25(4):302-13. 